\title{
Speaking Up: Opening Dialogue with Pre-service and In-service Teachers about Reading Children's Books Inclusive of Lesbian and Gay Families
}

Teresa M. Bouley

Follow this and additional works at: https://digitalscholarship.unlv.edu/jpme

\section{Repository Citation}

Bouley, Teresa M. (2011) "Speaking Up: Opening Dialogue with Pre-service and In-service Teachers about Reading Children's Books Inclusive of Lesbian and Gay Families," Journal of Praxis in Multicultural Education: Vol. 6: No. 1, Article 4.

DOI: $10.9741 / 2161-2978.1050$

Available at: https://digitalscholarship.unlv.edu/jpme/vol6/iss1/4

This Article is protected by copyright and/or related rights. It has been brought to you by Digital Scholarship@UNLV with permission from the rights-holder(s). You are free to use this Article in any way that is permitted by the copyright and related rights legislation that applies to your use. For other uses you need to obtain permission from the rights-holder(s) directly, unless additional rights are indicated by a Creative Commons license in the record and/ or on the work itself.

This Article has been accepted for inclusion in Journal of Praxis in Multicultural Education by an authorized administrator of Digital Scholarship@UNLV. For more information, please contact digitalscholarship@unlv.edu. 


\section{Speaking Up: Opening Dialogue with Pre-service and In-service Teachers about Reading Children's Books Inclusive of Lesbian and Gay Families}

\section{Theresa M. Bouley}

-For me to teach gay/lesbian issues in schools would be like teaching Spanish. I don't speak Spanish.l - Pre-service teacher candidate when discussing reading a children's book depicting all families inclusive of same-sex families

Educator/writer Vivian Gussin Paley defines our ultimate goal as teachers in a democratic society to be -helping children become kind and caring participants in a world that includes everyonel (Starting Small, 1997, p. iii). Children of gay and lesbian families, like all children, have a right to attend schools with administrators, teachers, and materials prepared to meet their individual, social, emotional, and academic needs. Yet, the heterosexist assumptions of administrators and teachers in elementary schools based on heteronormativity have resulted in curricula and pedagogy that fail to acknowledge and therefore meet the needs of gay/lesbian families (Kozik-Rosabal, 2000).

In 1993 Friend wrote, -Until recently, serious discussions of how inequalities in terms of sexual orientation are reproduced and sanctioned by schooling have been absent in the social analyses of diversity, equity, and power in education\| (Choices, Not Closets: Heterosexism and Homophobia in Schools, p.210). I strongly disagree with the notion that heterosexism and homophobia are included in discussions, even recently, when it comes to the day to day running of schools. In my experience few are discussing this - sensitive\| topic. As a result, there is pervasive silencing of gay/lesbian families in American schools.

One of the best ways to include all family structures in classroom practice is through children's literature. While more and more quality books depicting family diversity, inclusive of gay and lesbian families, are published every year, it is often the unknown discourse surrounding such readings and the unknown support of the teacher that keeps these books from even entering preschool through grade four classrooms.

Theresa Bouley is an Associate Professor in the Center for Early Childhood Education at Eastern Connecticut State University. She specializes in the areas of early childhood education, reading and language arts, and critical literacy. Her research and writings have mostly been in the areas of multicultural education focusing on multicultural literacy and literature. She regularly attends the annual international NAME conference as well as the annual NECME conference. She has a Ph.D. in Curriculum and Instruction from the University of Connecticut.

It is highly common that one avoids any task for which they are not efficacious. 
Starting dialogue related to any sensitive topic is a risk if one does not feel a sense of self-efficacy in their ability to - handlell whatever comes up. As a result of the silencing of same-sex families and issues in schools, teachers have had little to no practice talking about such issues neither with young children, peers, parents, nor administrators. This practice, practice talking, is a necessary step in building their self-efficacy to read books depicting all families and handle any discussions or challenges that arise. This practice is the focus of this paper and a critical step in ending the silence.

\section{We Are Here and We Are Queer}

Children of Lesbians and Gays Everywhere (COLAGE, 2001) estimates there are over ten million children of gay, lesbian, or bisexual parents in the United States. Others estimate the range to be vast and anywhere from -2 million to 8 million lesbian and gay parents who have between 4 and 14 million childrenll (KozikRosabal, 2000, citing Casper \& Schultz, 1999, citing Patterson, 1992, 1995). In addition, numerous children have extended family members, aunts, uncles, grandparents, as well as siblings or family friends who are lesbian/gay/bisexual/transgendered (LGBT).

The co-directors of COLAGE (2001) have stated, - Those of us raised in alternative families, especially gay and lesbian families, have grown up feeling invisible without knowing why. As the next generation grows up, they must have resources in which they can see themselves reflected and therefore validated.ll

As with all marginalized students, including students with gay/lesbian parents or family members, schools have historically and currently failed to produce environments that - provide for the optimal development of children and support for their familiesll (The National Association for Early Childhood Education (NAEYC) Code of Ethical Conduct, pg. 6). In my own research, talking with numerous elementary teachers, principals, and district superintendents, I found not only a lack of children's literature and curriculum inclusive of same-sex families but also a pervasive lack of communication on this subject. The majority of those interviewed were unaware of any school policies that may include same-sex families in curriculum, and they were also totally unaware of whether or not they would be supported if they chose to simply read books inclusive of all families (Bouley, 2007).

It is critical that we open discourse relating to the inclusion of gay/lesbian families in elementary schools for optimal development of all children. All children benefit from an education that is open and equitable. Providing this model of social justice would be instrumental in preparing children to develop a sense of empathy necessary to live in a pluralistic society. 


\section{The Role of the Teacher}

Teachers are in the ideal position to help children develop a sense of empathy and affirmation of diversity. Haim Ginott in Teacher and Child (1976) wrote:

I've come to the frightening conclusion that I am the decisive element in the classroom. It is my personal approach that creates the climate. It is my daily mood that makes the weather. As a teacher, I possess a tremendous power to make a child's life miserable or joyous. I can be a tool of torture or an instrument of inspiration. I can humiliate or honor, hurt or heal. In all situations, it is my response that decides whether a crisis will be escalated or de-escalated and a child humanized or de-humanized.

For the early childhood or elementary teacher it is almost easy to facilitate a sense of social justice in young children mostly because they have it already. Young children are keenly aware of fairness. They know when something is unfair and often strongly object. They also can be extremely empathetic. In one of her many books discussing exactly this, Vivian Paley shares numerous stories of how children continually express their strong empathetic and compassionate nature.

Paley believes the ultimate role of the teacher is, - To be nice. To set the model for niceness. To be nice to all the children all the time.\| Certainly, a young child would feel a sense of injustice if his classmate was too scared to draw a picture of his family because he didn't feel it was safe to share he had two dads. Hopefully, so would the adults involved.

\section{The Power of Books}

The most age appropriate way to include lesbian and gay families in elementary classrooms is through children's literature. It is a common occurrence that elementary teachers read books about families and ask children to share their family visually, either through pictures, or writing, etc. This is highly problematic for children from same-sex families if they have never seen their family represented in the books read by the teacher. There are numerous children's books that depict a wide variety of family structures and are inclusive of families with two dads or moms. Seeing their families represented in books is critical for all children on so many levels. The theoretical framework of much of the research in reading (e.g., Braugner \& Lewis, 1997; McQuillan, 1998; Moustafa, 1997, Smith, 1985) suggests that literacy is not simply the comprehension of a text but a means through which individuals participate in constituting themselves and their world. From a multicultural perspective, students from non-mainstream cultures can profit from having opportunities for understanding and developing pride in their heritage and for building a positive self-concept. Furthermore, literature can be a vehicle to foster cultural awareness and appreciation. Our culturally diverse population challenges educators to provide literacy instruction that reflects the 
variety of our students' experiences and backgrounds (Au, 1993; Routman, 1996). As children read multicultural literature they are constantly making connections between the new information and their previous experience, knowledge, and beliefs. The discourse evoked when reading such literature is critical in helping children to make sense of the text, themselves, and their world (Christensen, 1997). It is through these discussions that both teachers and children can begin to develop a sense of empathy, acceptance, and confidence in relating to members of the lesbian and gay community and the issues they face. Teacher awareness, access, and inclusion of children's literature depicting same-sex families are important steps. Yet, increasing teacher's self-efficacy in reading these resources is critical.

\section{Self-Efficacy and Outcome Expectancies}

Bandura (1986) proposed self-efficacy as a mechanism of cognitive selfevaluation that mediates skilled performance. He defined self-efficacy as a person's judgments of her or his ability to perform an activity and the effect this perception has on the ongoing and future conduct of the activity. Bandura (1986) believed that competent functioning requires both skills and self-beliefs of efficacy to use them effectively. He saw self-efficacy as a generative mechanism through which persons integrate and apply their existing cognitive, behavioral and social skills to the performance of a task. According to Bandura (1997), success is only attained after one generates and tests alternative forms of behavior and strategies. This problem-solving requires persistent effort. Bandura believed that those who may have self-doubts about their abilities abort this generative process if initial efforts prove deficient. Thus, self-efficacy is expressed as personal confidence in the ability to successfully perform tasks at a given level. It is concerned not with the skills one has, but with the judgment of what one can do with whatever skills one possesses and determines the effort people will put forth as well as how long they will persist at a given task (Bandura, 1977).

Bandura (1986) distinguished judgments of personal efficacy from responseoutcome expectations. Outcome expectancies are beliefs about contingent relations between successful task performance and received outcomes.

-Perceived self-efficacy is a judgment of one's capability to accomplish a certain level of performance, whereas an outcome expectation is a judgment of the likely consequence such behavior will producell (Bandura, 1986, p. 391). Outcome expectancies mediate task performance by providing a cognitive appraisal of the likely outcomes of successful task performance and the likelihood that successful performance will lead to the attainment of goals. Bandura differentiates between efficacy and outcome judgments because -individuals can believe that a particular course of action will produce certain outcomes, but they do not act on that outcome belief if they question whether they can actually execute the 
necessary activities\| (Bandura, 1986, p. 392).

Teachers simply will not read such books if either they lack self- efficacy to do so (they may feel like they are opening themselves up to potentially sensitive dialogue) and/or they expect negative outcomes. Yet, teachers have expressed that discussions around sensitive topics such as this are often unplanned and they feel they are caught unprepared to either engage in a conversation or handle a situation as they would have liked. By reading children's books inclusive of same-sex families, or on any topic of social justice, teachers will realize that rarely do children bring up the issues they see as sensitive. Yet, if they do, then getting practice with this sensitive dialogue is instrumental in developing a more efficacious attitude to handle whatever comes up. First, and perhaps most important, preparing for these discussions is also effective at helping us in examining our own beliefs and biases.

\section{The Examination}

Linda Lantieri and Janet Patti in Waging Peace in our Classrooms (1996) state, -One of the biggest challenges in moving towards a classroom capable of transforming kids is that as teachers we have to transform ourselves\| (p.122). They believe that it is only when we examine our own biases and prejudice that we can -help young people understand such deep concepts as what racism is and how our society has oppressed people because of their differences\| (p.122). Irwin (1996) purports that the process of becoming nonsexist, multicultural persons is lifelong and entails - learning by listening, asking and being open to others ${ }^{6}$ perspectives $\|$ as well as admitting to our - unconscious biases and the unwitting mistakes that we have madell (p. 136). Bell Hooks suggests in Teaching to Transgress (1994) that teachers can only teach to the level of their own enlightenment. This raising of consciousness is critical of all individuals, not teachers alone. Teacher educators, administrators, parents, and community members can all commit to the principles of the peaceable, equitable classroom.

Since change is not an easy process, and -change in self is perhaps the most difficult of alll (Lantieri and Patti, 1996, p.122) it is unlikely that members of the school community will raise their levels of consciousness without a challenge for change.

\section{The Challenge}

As a teacher-educator of early childhood/elementary literacy, I have always been mindful to include children's literature depicting lesbian and gay families and youth in my undergraduate and graduate courses. I purchase available books, share titles with students, read them in classes, and encourage discussion. As mentioned, I have spoken with numerous teachers, principals, librarians, and superintendents 
about their practices and school policies relating to classroom inclusion of such books (Bouley, 2007).

I have found the reading of and discourse related to multicultural children's books to be just as transformative for adults as it is for children. Sharing and reading books depicting lesbian and gay families in class has resulted in the opening of rare and at times painful discourse. These discussions have helped to raise students ${ }^{6}$ and my own awareness of our beliefs and unconscious biases as well as our understanding of the need for change.

It is critical then that I first develop an interpersonal environment that is conducive to these discussions. It is worthy to note that my students travel through four semesters of course work as a cohort group, so they really get to know each other. They have courses with me during both core one and two, so they develop a certain comfort level with me as well. During both of these courses, I start each class by sharing children's literature that is multicultural and often great for eliciting discussions related to social justice. I encourage students to be open in sharing their perspectives, feelings, and beliefs. Early on in the first semester, students and I develop simple ground rules such as respect, open mindedness, confidentiality, and compassion. I have realized that students watch carefully to confirm that I model these ground rules consistently. I share with students Irwin's (1996) belief that the process of becoming nonsexist, multicultural persons is lifelong and entails -learning by listening, asking and being open to others ${ }^{6}$ perspectives $\|$ as well as admitting to our - unconscious biases and the unwitting mistakes that we have madel (p. 136). Demonstrating to students that of course I am not void of bias is extremely liberating for them and powerful in opening up honest classroom discourse. Also, an important part of establishing this safe, risktaking environment has been sharing Patti De Rosa's (of the organization CrossCultural Consultation) Guidelines for Challenging Racism and Other Forms of Oppression (Lantieri and Patti, 1996) as she helps us to remember that, - None of us remain untouched by the discriminatory messages in our society.\| In creating this environment my main goal has been, - to teach students how to listen, how to hear one another\| (Hooks, 1994, p. 150) and how to listen to themselves. This is perhaps the most challenging of all.

\section{The Conversations}

The conversations have not always been easy, for any of us. But, we have talked. Students have shared their fears, beliefs, confusions, and frustrations. I have felt vulnerable, elated, and deflated. We have all learned through this practice talking and have learned to practice listening, objectivity, and empathy. In my experience, no other topic has been more difficult to discuss. One might suggest this is because the students and I have not had much practice openly discussing 
homosexuality, heterosexism, and/or our responsibilities to lesbian, gay, bisexual, transgendered (LGBT) families. Hooks (1994) suggests that the existing pedagogical structure in schools fails not only to include but avoids at all cost open critical discourse on difficult subjects. Christensen (1992) eloquently explained the ideology behind what has been referred to as fear of naming: - Topics like racism and homosexuality are avoided in most classrooms but they seethe like open wounds. When there is an opening for discussion, years of anger and pain surfacell (p. 14). There has been evidence of both.

Mostly our discussions consist of students sharing their own beliefs or fears. Very rarely do students actually respond to or challenge each others' beliefs. It is clear that initially many students lack self-efficacy in their ability to engage in discourse on this topic as they do not persist. Rather, they share and move on or remain silent. This lack of confidence in critical discourse often results in a student coming to my office at a later time to share his/her thoughts/concerns about another student's in-class comment. For example, one day after I read the book Families by Susan Kuklin (2006), a discussion transpired around whether or not teachers were allowed to read books - like that (the most common response). It should be noted that this book is simply a collection of children's stories about their families and depicts all types of family structures inclusive of same-sex families. It is not a didactic book specifically depicting a same-sex family. Yet some students shared that they would worry that parents might complain, and they might get in trouble. (This is a conversation we have every semester. Both undergraduate and graduate students question whether they would be -allowedl to read these books and whether principals would support them if parents complained, which is clear evidence of the silencing). While discussing this issue one student said, - For me to teach gay/lesbian issues in schools would be like teaching Spanish. I don't speak Spanish.\| This statement deeply offended at least three students who came to my office to share their concerns. Yet, all three students said they would not have been comfortable expressing their thoughts and feelings to the student in class. When we discussed why that was, students demonstrated an emotional quality that likely contributed to their silence. In other words, they felt angry. They expressed it would be easier to debate topics for which they had less emotion; topics that didn't have to do with the discrimination of people. This is a great example of Bandura's outcome expectancy, a judgment of the likely consequence a behavior will produce, as these students expected two results as

the outcome of their behavior; one, they would become upset and two, there may be a fight or - uncomfortablell period. Either way it would be a bad thing.

However, graduate students have been slightly more efficacious in expressing their opinions and disagreements. In one graduate class after I had read Felicia's 
Favorite Story by Leslea Newman and Adriana Romo (2002), one student said it would be against her religion to teach LGBT issues in schools (interestingly the students who share their objection-and generally there have been few- use the words - teach LGBT\| when referring to reading books including or depicting gay/lesbian families). In this case, another student said she felt that, as teachers, our job was to advocate for all children, and in so doing, we should - check our beliefs, religious or other, at the door.ll Another student shared she was in agreement by stating, - As public school teachers we are not allowed to teach our religious beliefs to our students so it would make sense that we should also not use our religious beliefs to make classroom decisions like this. $\|$ As expected, it is common that the topic of religion enters our discussions. Most students share that their desire and obligation to advocate for all children must dictate their instructional decisions more than their religious or personal beliefs. In this way they seem to see the inclusion of literature depicting gay/lesbian families as important to children from gay/lesbian families only.

The common response has been that these pre- or in-service teachers would feel more comfortable including gay/lesbian families in their discussion on families if they actually had a child in their room with a gay parent(s). It appears that these students/teachers are assuming that they would always be aware of a gay/lesbian parent/family member, which is not necessarily true. Even more important, it further suggests that they don't see including LGBT families in their multicultural curriculum as beneficial to all children. When a few students/teachers were asked how this exclusion was different from waiting until there is a member of a specific culture or ethnic group in their class before reading a book depicting that culture, their response was often, - I hadn't thought of it that way!"

Interestingly enough, much of the dialogue that stems from my reading a book either including or depicting same-sex families centers around these same points that are raised by Series Editor James Sears in the forward of Beyond Diversity Day: A Q\&A on Gay and Lesbian Issues in Schools (Lipkin, 2004),

-Lipkin equips citizens for questions that will most likely be voiced by the guardians of the sexual status quo: Why should the topic of homosexuality be included in the curriculum? Isn't teaching about homosexuality only about sex? Can studying about homosexuality make a student gay? Is this not more propaganda than education?\| (p.x)

It seems teachers are either pondering these questions or, more often, fear the potential complaints from the parents of their children will stem from their own answers or biases to these questions. The most common feeling expressed has been fear; fear of parent complaints and uncertainty of administrator support. This outcome expectancy, that others will react negatively, is pervasive and powerful, as it keeps these individuals from reading these books even though the majority of them felt strongly about the need to do so. 
Many, many questions have been raised with very few answers. Are other teachers in my school reading these books? Would my principal support me if a teacher complained? Do we have a school policy on this? Would I lose my job? Are lesbian and gay families included in our social studies curriculum? As a result, undergraduate students have begun to ask practicum teachers and graduate students have asked their peers and administrators for answers. This opening of dialogue is the necessary first step.

Students often share that they are lacking self-efficacy in reading books about or inclusive of same-sex families with children. They worry about what the children might ask and how they would be able to answer those questions - carefully.\| A few students have worried that the children will ask questions that are sexual in nature expressing the voice, as Sears points out above, of the sexual status quo. When this has come up, other students and I have seized the teachable moment to demonstrate (often with books we happen to have on hand) how in many children's books, straight parents even engage in sexual behavior such as kissing and hugging, yet young children don't see these behaviors as sexual or ask questions about sex. A more common explanation for students' expressed discomfort relates to the ideology mentioned above known as - fear of naming.\| Students have said they feel uncomfortable discussing — sensitive issues\| with children mostly because of their fear of the unknown: What will they ask? What will they tell their parents? This is one reason why I have videotaped myself reading books inclusive of same-sex families to children. Students can watch these read-alouds and see how children actually do not ask about sex or sexuality or most anything else they often fear they will.

Overwhelmingly the pre- and in-service teachers in my classes have expressed a deep and genuine desire to advocate for all of the children and families in their classrooms. Yet publicized homophobia and heterosexism and systematic silencing in schools has, so far, left them afraid, for the most part, to include gay and lesbian families in their practice. While self-efficacy in reading books related to this sensitive topic is important, it is less likely that these students will do so if they harbor such negative outcome expectancies. A shift in this thinking will only happen with open dialogue amongst all those involved.

\section{Conclusions}

The classroom (and office) discourse we have had on this issue has been a challenge to change us all. Through these conversations, I believe students have come to understand that ending the silencing and oppression of LGBT families in schools would begin only with the opening of safe, community-wide dialogue. Students have shared that their participation in this dialogue has increased their own personal comfort level and therefore increased the likeliness that dialogue 
will remain open. Their heightened self-efficacy to discuss such a sensitive topic will hopefully result in an increased comfort level in reading books that may open up - sensitive-issuell dialogue with the children in their classrooms. A further result may be explicit effort on these teachers' behalf to keep the dialogue open with their peers, parents, principals, and superintendents and therefore act as change agents in their school communities. This is critical as it would alter teacher's outcome expectancies and increase the likeliness that they will persist. Students have expressed that they feel more efficacious and empowered to take the risks necessary for change. It certainly helps that they are more knowledgeable about children's literature depicting gay and lesbian families (see attached bibliography) and the benefits of including such literature in their classrooms. Yet, and sadly, it is also evident that students have come to understand that, for some teachers, embracing diversity and teaching multiculturally does not include embracing same-sex families.

\section{References}

Au, K. H. (1993). Literacy instruction in multicultural settings. Orlando, FL: Harcourt Brace College Publishers.

Bandura, A. (1977). Social learning theory. Englewood Cliffs, NJ: Prentice Hall.

Bandura, A. (1986). Social foundations of thought and action: A social cognitive theory.Englewood Cliffs, NJ: Prentice Hall.

Bandura, A. (1997). Self-efficacy: The exercise of control. New York: W. H. Freeman.

Bouley, T. (2007). The Silenced family: Policies and perspectives on the inclusion of children's literature depicting gay/lesbian families in public elementary classrooms. In I. Killoran \& K. Pendleton Jimenez (Eds.), —Unleashing the unpopularll: Talking about sexual orientation and gender diversity in education (pp. 140-147). Olney, MD: Association for Childhood Education International.

Braunger, Jane \& Jan Lewis. 1997. Building a Knowledge Base in Reading. Northwest Regional Educational Laboratory.

Christensen, L. (1992). Tales from and untracked class. Rethinking Schools, 2, (1), 1416.

COLAGE. (2001). Children of Gays and Lesbians Everywhere. Retrieved November, 2005, from http://www.colage.org/research/facts.html.

Friend, R. A. (1993). Choices, Not Closets: Heterosexism and Homophobia in Schools. In L. Weis, and Fine, M. (Eds.), Beyond Silenced Voices (pp. 209-235). Albany, NY: State University of New York Press. 
Ginott, H. (1976). Teacher and child. New York: Avon. Hooks, B. (1994). Teaching to transgress: Education as the practice of freedom. New

York: Routledge. Irwin, J. (1996). Empowering ourselves and transforming schools: Educators making a difference. Albany, NY: SUNY Press.

Kozik-Rosabal, G. (2000). Well, we haven't noticed anything bad going on," said the principal: Parents speak about their gay families and schools. Education and Urban Society, 32(3), 368-389.

Lantieri, Linda \& Janet Patti. 1996. Waging Peace in Our Schools. Boston: Beacon Press.

Lipkin, A. (2004). Beyond diversity day: a q \& a on gay and lesbian issues in schools.

Lanham, Maryland: Rowman and Littlefield Publishers. McQuillan, J. (1998). The literacy crisis: False claims, real solutions. Portsmouth, NH:

Heinemann. Moustafa, M. (1997). Beyond traditional phonics: Research discoveries and reading instruction. Portsmouth, NH: Heinemann.

National Association for the Education of Young Children (2005). Position Statement of the National Association for Education of the Young Child. Code of ethical conduct and statement of commitment. Washington, DC: National Association for the Education of Young Children.

Paley, V. (1996) The Kindness of Children. Routman, R. Literacy at the crossroads: Crucial talk about reading, writing, and other teaching dilemmas. Portsmouth, NH: Heinemann.

Smith, F. (1985). Reading without nonsense. New York, NY: Teachers College Press. Teaching Tolerance (1997). Starting Small: Teaching Tolerance in Preschool and the early grades. A project of the Southern Poverty Law Center.

\section{Children's Books Depicting or Inclusive of LGBT Families}

1) Families by Susan Kuklin. Hyperion, 2006. ISBN 078680822-5.

This book contains wonderful interviews with children from 15 different families. These families represent all types of diversity including two families with lesbian or gay parents. The book is written in the children's words and demonstrates the pride they feel for their families and themselves.

Theme: Families Diversity: Family, cultural, ethnic, religious, lesbian and gay Age: Preschool-Grade 6 
2) How My Family Came to Be: Daddy, Papa and Me by Andrew Aldrich. Illustrated by Mike Motz. New Family Press, 2003. ISBN 0974200808.

This is an uplifting and beautiful story of how a gay couple adopted their son. The fact that the couple is white and their son is African American added another facet to the story, bringing a measure of visibility to the growing number of biracial, bicultural families in our society. The illustrations are playful and add an element of emotional depth to the straightforward narrative of how this family came to be.

Theme: Adoption Diversity: Cultural, ethnic, gay dads Age: Preschool-Grade 3

3) While You Were Sleeping by Stephanie Burks. Illustrated by Kelli Bienvenu. Trafford Publishing, 2004. ISBN: 1412028531.

Two women learn that a birthmother has chosen them to adopt her newborn baby boy. The story begins with the excitement and anticipation these two mothers feel for their new son. The joy they feel when bringing him home for the first time is evident in this beautiful story about love. The colorful illustrations warmly express the true love these two moms have for their newly adopted son.

Theme: Adoption Diversity: Culture, non-traditional families, lesbian families Age: Preschool-Grade 3

4) Antonio's Card; La Tarjeta de Antonio by Rigoberto Gonzalez and illustrated by Cecilia Concepcion Alvarez. Children's Book Press, 2005. ISBN 0-89239-2045

Antonio is preparing a card for Mother's Day for his mom and her partner. When the children in his class make fun of Leslie, Antonio isn't sure how to express his feelings for both women.

Theme: Family differences Diversity: Family, culture Age: Preschool-Grade 4

5) And Tango Makes Three by Justin Richardson and Peter Parnell and Illustrated by Henry Cole. Simon \& Schuster, 2005. ISBN 0-689-87845-1

This is a true story of two male penguins who live in Central Park Zoo and who have lived side by side for years. When a female penguin laid two eggs and demonstrated she could only take care of one, Roy and Silo got their chance to work together towards having a family.

Theme: Family differences Diversity: Family Age: Preschool-Grade 4

Bouley: Speaking Up: Opening Dialogue

6) King \& King by Linda De Hann and Stern Nijland. Tricycle Press, 2002. ISBN 1582460612 . 
The king and queen are searching for a princess for their son. When a brother accompanies a prospective princess, the prince and his parents find out together that it is not a princess he desires, but a prince.

Theme: Coming out, family love and acceptance Diversity: Diverse family structures Age: 1-3

7) Mama Eat Ant, Yuck! by Barbara Lynn Edmonds. Illustrated by Matthew Daniele. Hundreth Munchy Publishers, 2000. ISBN 0965670023.

This simple rhyming text tells a funny story in the family life of one-year-old Emma, her Mama and Mommy, and her siblings. The repetition of the child-friendly title throughout the book makes this text appropriate for two-year-olds who can then participate in the reading.

Theme: Family adventures Diversity: Diverse family structures Age: Toddlers-Grade 1

8) The Sissy Duckling by Harvey Fierstein. Illustrated by Henry Cole. Simon \& Schuster Books, 2002. ISBN 0689835663.

Elmer is not like the other boy ducklings. He likes to do things that only the girls are supposed to do. Elmer demonstrates that even though he is a - big sissy,ll he is brave, unique, and equally valuable. The eventual support of his family gives him added strength to be himself.

Theme: Gender stereotypes, family acceptance, self-worth Diversity: Acceptance of differences, emphasizes similarities Age: 1-3

9) Molly's Family by Nancy Garden. Farrar, Straus and Giroux, 2004. ISBN 0374350027.

Molly's kindergarten class is preparing for Open School Night and decides to decorate the classroom for visiting parents. Molly draws a picture of her family, which includes Mommy, Mama Lu and her puppy, Sam. Some of the other children in her class don't understand how families can have two mothers. Molly is hurt by the reaction of her peers but her parents and teacher explain to her (and all of the students) that families are different. The other children then begin to describe how their families are different. Illustrations are expressive and colorful.

Theme: Family differences Diversity: Family, culture Age: Preschool-Grade 3

10) Best Best Colors/Los Mejores Colores by Eric Hoffman. Illustrated by Celeste Henriquez. Redleaf Press, 1999. ISBN 1884834698.

Nate's two moms help him to understand that he can have more than one favorite color and one best friend. This is one in a series of books titled, Anti-Bias Books for Kids: Teaching Children New Ways to Know the People Around Them. All books in the series 
are in English and Spanish and include information for parents, caregivers, and teachers on how to reinforce and help preschool children to learn cooperation and respect for diversity.

Theme: Cooperation and respect for diversity. Diversity: Multicultural/multiethnic, diverse family structure Age: Preschool-Grade 3

11) The Harvey Milk Story by Kari Krakow. Illustrated by David Gardner. Two Lives Publishing, 2001. ISBN 096744683-x.

Harvey Milk was the first openly gay elected city official in the United States. Above all else, this biography sends the clear message that a single individual can make a difference. Harvey Milk was an extremely courageous man who fought for civil rights at a time when gay people had no legal protection. The author tells Milk's life story effectively and appropriately from his childhood to his assassination. Epilogue and author's notes included.

Theme: Individuality, gay civil rights, hate crimes, government Diversity: Gay/lesbian, cultural diversity Age: Grade 2 and up

12) Heather Has Two Mommies by Leslea Newman. Illustrated by Diana Souza. Alyson Publications, 1989. ISBN 155583180X.

Heather has two mommies. When she starts school, Heather and her new friends quickly realize that there are many different kinds of families. As expected, since this book was one of the first to break the silence and tell the story of a same sex family, the focus or theme is limited.

Theme: Diverse family structures

Diversity: Same sex families, family diversity Age: 1-3

13) Heather Has Two Mommies: 10th Anniversary Edition by Leslea Newman. Illustrated by Diana Souza. Alyson Publications, 2000. ISBN 1555835430.

In this new edition, Newman makes changes to Heather's story based on feedback she has received over the years. In addition, to the text being shorter (making it suitable for younger listeners), Newman removed the section which described Heather's conception and birth. This allows Newman's message that love is the most important family trait to be heard loud and clear.

14) Saturday is Pattyday by Leslea Newman. Illustrated by Annette Hegel. New Victoria, 1993. ISBN 0934678510.

In this story, Frankie is sad and hurt when his two mommies separate. Frankie soon learns that although he no longer lives with Patty, she is still a part of his life. He finds comfort in knowing that he will be spending his Saturdays with Patty. 
Theme: Same sex families, separation Diversity: Family diversity Age: Grade 1-3

15) The Family Book by Todd Parr. Little, Brown and Company, 2003. ISBN 0316738965.

In this book, Todd Parr demonstrates that there are many different ways to be a family. Families are different colors, live in different locations, eat different foods, and have varying members. Yet, all families like to help and hug each other, celebrate special occasions together, and love each other. The many differences and similarities of families are celebrated in this simple, yet wonderful story.

Theme: Family diversity Diversity: Family, culture, ethnicity Age: Preschool- Grade 3

16) The Mommy Book by Todd Parr. Little, Brown and Company, 2002. ISBN 0316608270 .

Similar to the Family Book, yet this book focuses on moms. While all moms are different, they have many similarities. In particular, they all love their children. Some moms drive motorcycles, some drive vans, some work at home, others work in largebuildings, some have short hair, some have long. Yet, all mommies like to hang out with their children and watch them sleep.

Theme: Individuality, family diversity Diversity: Family, individually Age: PreschoolGrade 3

17) The Daddy Book by Todd Parr. Little, Brown and Company, 2000. ISBN 0316.

In this book, it is Daddies' turn to be different yet similar. All dads may look and act different, but all dads like to be with you and love you.

Theme: Individuality, family diversity Diversity: Family, individually Age: PreschoolGrade 3

18) It's Okay to be Different by Todd Parr. Little, Brown and Company, 2001. ISBN 0316666033.

In this book, Parr makes it clear that it is not only okay to be different but also demonstrates great insight into the feelings and social development of young children. For example, Parr states it is okay to do something nice for yourself, to be proud of yourself, to be embarrassed or to be mad. It is also okay to have different families or to come from different places. A simple yet powerful message!

Theme: Individuality, family diversity Diversity: Family, individuality, culture, ethnicity, linguistic, differing needs Age: Preschool-Grade 3

19) Who's in a Family? by Robert Skutch. Illustrations by Laura Nienhaus. 


\section{Tricycle Press, 1995. ISBN 188367266x.}

Skutch demonstrates that there are many different kinds of families, and while families may look alike, they are all unique. The author discusses traits of differing family structures and then compares them with a few animal families. For example, some children live in families with only their mothers not unlike chimpanzee families where mama chimp raises her young. While this comparison may seem awkward, the author effectively relates diversity in families to something many children know about, animals.

Theme: Family structures, family activities Diversity: Family, culture, ethnicity Age: Preschool-Grade 3

20) The Daddy Machine by Johnny Valentine. Illustrated by Lynette Schmidt. Alyson Wonderland, 2004. ISBN 1555838464.

Valentine brings us into the house of two children who live on Grove Street. When their two moms had to leave for work, the children decided to make a daddy machine. When it actually works and turns out 50 plus dads, they have many great adventures! A playful text that brings visibility to happy gay/lesbian families.

Theme: Gay/lesbian families Diversity: Cultural, ethnicity Age: Grade 1-3

21) One Dad, Two Dads, Brown Dad, Blue Dads by Johnny Valentine. Illustrated by Melody Sarechy. Alyson Wonderland, 1994. ISBN 1555832539.

Two children share their family structures-one has two dads and one has a mom and dadand in so doing realize that their dads are not really so different after all. Valentine uses color, as a concrete way to differentiate between family structures as Lou has two dads that are blue. This is a very easy-to-read, Dr. Seuss-like text tha, although simple, exposes many stereotypes or misconceptions about gay dads. For example, the child with two blue dads is asked, - If they hug you too hard will the color rub off?॥ A fun and powerful book.

Theme: Family structure, gay dads, gay stereotypes Diversity: Families, culture Age: Preschool-Grade 3

22) My Two Uncles by Judith Vigna. Albert Whitman, 1995. ISBN 080755507.

Elly has two favorite uncles. One is her dad's brother, and the other is his partner. In this relevant story, Elly is trying to understand why one of her favorite uncles is not invited to a family celebration. In this text, Vigna - offers a powerful message about the power of understanding and the possibilities of change.\|

Theme: Family structure, homophobia, love and acceptance, change Diversity: Families Age: Grade 1-3

23) Is Your Family Like Mine? by Lois Abramchik. Illustrated by Alaiyo 
Bradsaw. Open Heart, Open Mind, 1993. ISBN 0964714507.

Five-year-old Armetha lives with her two mothers who encourage her to learn something new each day. When she turns to her friends and asks, - Who lives in your family?\| she discovers that they come from all different families. Illustrated in black and white.

Theme: Family diversity, lesbian and gay parents, love and acceptance

Diversity: Multicultural characters Age: K-Grade 3

24) ABC: A Family Alphabet Book by Bobbie Combs. Illustrated by Desiree Keane and Brian Rappa. Two Lives Publishing, 2000. ISBN 0967446813.

This is a simple alphabet book that depicts children having fun with their alternative families. Children on each page demonstrate typical family activities done with their two moms or dads. Young children can partake in the fun while learning both the alphabet and family diversity.

Theme: Gay/lesbian families, alphabet book, family traditions Diversity: Culturally and ethnically diverse characters Age: Preschool-Grade 1

25) 123: A Family Counting Book by Bobbie Combs. Illustrated by Danamarie Hosler. Two Lives Publishing, 2000. ISBN 0967446805.

In this book young children can enjoy the same experiences as stated in the $\mathrm{ABC}$ book while practicing their counting skills.

Theme: Gay/lesbian families, counting book, family traditions Diversity: Culturally and ethnically diverse characters Age: Preschool-Grade 1

\section{JPME APA 5.11 Correction Notice: Speaking Up}

Journal of Praxis in Multicultural Education April, 2011 Volume 6 Issue 1 Article 4 Pages 3-18

Speaking Up: Opening Dialogue with Pre-Service and In-Service Teachers about Reading Children's Books Inclusive of Lesbian and Gay Families

By, Teresa M. Bouley

Location of Errors: Page 4, Theoretical Framework, 9 sentences in paragraph $2 \& 3$

Error One: 4 sentences have full attribution yet quotation marks are missing. Corrected Sentences: 
Pg. 4 Line 19: Bandura (1986) believed that "competent functioning requires both skills and self-beliefs of efficacy to use them effectively" (p. 391).

Pg. 4 Line 29: "It is concerned not with the skills one has, but with the judgment of what one can do with whatever skills one possesses" (Bandura, 1986, p. 391) and determines the effort people will put forth as well as how long they will persist at a given task (Bandura, 1977).

Pg. 4 Line 23: According to Bandura (1986, 1997), success is only attained after one generates and tests alternative forms of behavior and strategies (1986, p. 391).

Pg. 4 Line 25: This "problem-solving requires persistent effort" and Bandura (1986) believed that those who may have self-doubts about their abilities "abort this generative process if initial efforts prove deficient" (p. 391).

Error Two: In 5 sentences it appears to be another author's reference to an original source. Therefore Henck et al. and Shell et al. need to be referenced in text and then added to the reference list.

\section{Henck et al.}

Pg 4. Line 17: Bouley: He defined self-efficacy as a person's judgments of her or his ability to perform an activity and the effect this perception has on the ongoing and future conduct of the activity.

Corrected: Henck \& Melnick (1997) state, "Bandura defined self-efficacy as a person's judgments of her or his ability to perform an activity and the effect this perception has on the ongoing and future conduct of the activity" (p. 471)

Needed Added Reference: Henck, W.A., \& Melnick, S.A. (1997). The reader self perception scale (RSPS): A new tool for measuring how children feel about themselves as readers. The Reading Teacher, 48, 470-482.

\section{Shell et al.}

Pg 4 Line 21: Bouley: He saw self-efficacy as a generative mechanism through which persons integrate and apply their existing cognitive, behavioral and social skills to the performance of a task.

Corrected: Shell, Murphy, and Bruning (1989) state that Bandura saw self-efficacy as, "a generative mechanism through which persons integrate and apply their existing cognitive, behavioral and social skills to the performance of a task" (p. 91).

Pg 4 Line 27: Bouley: Thus, self-efficacy is expressed as personal confidence in the ability to successfully perform tasks at a given level.

Corrected: Shell et al. (1989) state that self-efficacy is "expressed as personal confidence in the ability to successfully perform tasks at a given level" (p. 91).

Pg 4 Line 34: Bouley: Outcome expectancies are beliefs about contingent relations between successful task performance and received outcomes. 
Corrected: Shell et al. (1989) define outcome expectancies as, "beliefs about contingent relations between successful task performance and received outcomes” (p. 91).

Pg 4 Line 39: Bouley: Outcome expectancies mediate task performance by providing a cognitive appraisal of the likely outcomes of successful task performance and the likelihood that successful performance will lead to the attainment of goals.

Corrected: Shell et al. (1989) further state that outcome expectancies, "mediate task performance by providing a cognitive appraisal of the likely outcomes of successful task performance and the likelihood that successful performance will lead to the attainment of goals" (p. 91).

Needed Added Reference: Shell, D. F., Murphy, C.C., \& Bruning, R.H. (1989). SelfEfficacy and outcome expectancy mechanisms in reading and writing achievement. Journal of Educational Psychology, 81, 91-100. 